\title{
Evaluation of the Opportunities for Prevention of the Periodontal Diseases Among the Pregnant Women in Tbilisi
}

\author{
Veriko Tevzadze, DM, PhD(s) PhD \\ Ketevan Nanobashvili, DM, PhD(s) PhD \\ Doctoral Program: Public Health, \\ University of Georgia, School of Health Sciences, Georgia
}

Doi:10.19044/esj.2021.v17n17p1

Submitted: 12 April 2021

Accepted: 12 May 2021

Published: 31 May 2021
Copyright 2021 Author(s)

Under Creative Commons BY-NC-ND

4.0 OPEN ACCESS

Cite As:

Tevzadze V. \& Nanobashvili K. (2021). Evaluation of the Opportunities for Prevention of the Periodontal Diseases Among the Pregnant Women in Tbilisi. European Scientific Journal, ESJ, 17(17), 1. https://doi.org/10.19044/esj.2021.v17n17p1

\section{Abstract}

Task: Although periodontal inflammatory diseases are very often during pregnancy, little is known about the risk factors that increase the frequency of periodontal disease incidence and affect its development during pregnancy. This descriptive study assesses the prevalence of periodontal diseases among pregnant women in Tbilisi, the impact of their socio-economic status, hygiene habits, and level of knowledge on their periodontal status. Methods: This was an observational, cross-sectional study conducted among pregnant women. The respondents were distributed by Gynecological Centers and districts in Tbilisi. The survey was conducted at 24 Gynecological Centers. The target group of the study was 222 pregnant women aged 18 to 45 living in Tbilisi. The tool used in this study is a Structured Electronic Questionnaire. The oral health of the target group representatives was assessed by periodontal indices, the CPITN-index, and OHI-Jack R.Vermillion's oral hygiene index. Data entry and statistical analysis were carried out using the statistical program SPSS 23.0. Results: The current pregnancy for most of the respondents (36\%) is the second, $53.2 \%$ of the pregnant women are in the second trimester of the pregnancy, 50,5\% of the respondents are bachelors' student or have completed a bachelor's stage of the study. Due to the employment status, $47.7 \%$ of them are housewives, and $61.1 \%$ evaluate their economical condition as satisfactory; $32,9 \%$ of the respondents have dental 
insurance, and only $13,3 \%$ use this insurance for this purpose. $68.8 \%$ of the pregnant women address the dentist only in case of pain or discomfort, $67.3 \%$ of them have bleeding gums, $66.5 \%$ of them feel pain or discomfort in the oral cavity and 59\% of them have swelling/pain in their gums. Only $9 \%$ of gynecologists recommend their patients plan a visit to the dentist. Pregnant women's awareness about the safety of dental manipulations is also quite low and it is $22.1 \%$. The statistical testing of the difference due to the qualitative variables was carried out using the Pearson's chi-square method; the index of signification $(\mathrm{p})$, which was less than 0.05 , at $(\mathrm{p}<0.05)$ was considered as statistically significant.

Keywords: Pregnancy, Periodontal diseases, Prevalence, Tbilisi

\section{Introduction}

Periodontal inflammatory diseases are the most common among dental diseases and the microbes play a main etiological role in their development. However, these diseases are multifactorial, and various local and general factors affect their origin and development. (Tonetti MS, Jepsen S, Jin L, Otomo-Corgel J. 2017); (Daniel Kandelman, Sophie Arpin, Ramon J Baez, Pierre C Baehni, Poul E Petersen.2012); (Eija Könönen,Mervi Gursoy, and Ulvi Kahraman Gursoy.2019).

The pain, discomfort, and tooth loss caused by the periodontal disease lead to functional and aesthetic disorders and prevents human's healthy integration into society. The relationship between the oral health of the pregnant woman and the normal growth and development of the fetus is also very important. Gingivitis of pregnant women is the most common problem in the gestational period, according to some studies, it is revealed in $40 \%$ of pregnant women, while other studies name 100\%. (Marin C, Segura-Egea JJ, Martínez-Sahuquillo A, Bullón P. 2005); (Oral care in pregnancy Zeynep Yenen, and Tijen Ataçağ. 2019).

The pregnancy causes physiological changes, including hormones. During the pregnancy, a reversible light inflammation of the gums occurs, called "gingivitis of pregnant women". The untreated gingivitis can lead to periodontitis in 30-100\% of pregnant women, which affects from 5\% to $20 \%$ of pregnant women. (Muwazi L, Rwenyonyi CM, Nkamba M, Kutesa A, Kagawa M, Mugyenyi G. 2014); (Morelli EL, Broadbent JM, Leichter JW, Thomson WM. 2018); ( Monika Pandey, Mradula Chauhan, and Shally Awasthi. 2017); (Panayiotis Kouis, Paraskevi Kinni, Angelos Rigas.2018); (Zeba Jafri, Ashu Bhardwaj, Madhuri Sawai, and Nishat Sultan. 2016).

In 1996 Offenbacher presented a hypothesis that periodontal diseases may be a potential risk factor for premature birth. After that Michael Kerry and others in 2020-2021 presented retrospective and connected studies in the 
Republic Rwanda and Romania present, which once again proves existence of this relationship. (Moneet Walia and Navdeep Saini. Offenbacher S, Lieff S, Boggess KA, Murtha AP. 2016); (Yang, Irene RN Hu,Yi-Juan. 2016); (Corwin EJ, Hogue CJ, Pearce B. 2017); (Michael S. Kerr, Stephen Rulisa, Harlan Shiau. 2021); (A Roman, F Ticala, A Soanca, A Ciurea. 2020).

In 1891 (Miller WD. 1891) Miller published the Focal Infection Theory. He considered that periodontal infection is a bacterial reservoir that can worsen systemic diseases. (Malvin E Ring. 2002). The endotoxins, obtained as a result of gram-negative bacterial infections, that contribute to the creation of the cytokine and prostaglandin (Interleukins (ILs)_1 $1 \beta$ (IL-1 $\beta$ ), IL6 , and tumor necrosis - factor $\alpha$ ), stimulate the childbirth, while proinflammatory mediators can pass the placental barrier and cause a fatal intoxication that leads to premature birth and birth of low weight newborn A hight concentration of cytokines among pregnant women causes damage to the uterine membrane, which in turn, leads to premature birth. (Sizzle F. Vanterpool, Kathleen Tomsin, Leticia Reyes. 2016); ( Mradula Chauhan, and Shally Awasthi.2017); (Shinwan Kany, Jan Tilmann Vollrath. 2019).

The potential pathological mechanisms of periopathogens, especially p.gingivali and f.nuceatum are also studied by other authors. For example, p.gingivalis can infect the syncytiotrophoblast, chorionic trophoblasts, decided cells and contribute to inflammation process by toll-like receptors (Gürsoy M, Pajukanta R, Sorsa T, Könönen E 2010); (Peter Chung, Rochelle Dumm, Nishiant Joshi, Yiping W Han.2010); ( J. Katz, K.T. Shiverick, T.A. Brown.2013).

Many infections undergo screening (cytomegalovirus infection, simple herpes virus infection, hepatitis B, hepatitis C, Hepatitis B with streptococcus infection, listeriosis) during the pregnancy period (antenatal surveillance program. 2018) and very little attention is paid to the periodontal inflammation.

\section{Material and Methods:}

This observational cross-sectional study was carried out to assess the prevalence of the periodontal disease among pregnant women, the impact of their socio-economic status, hygiene habits, and the level of knowledge to the pregnant women periodontal status. The target group of the study was 222 pregnant women aged 18 to 45 living in Tbilisi. The respondents were distributed by Gynecological Centers and districts in Tbilisi. The survey was conducted at 24 Gynecological Centers. The tool used in this study is a Structured Electronic Questionnaire, which does not contradict the ethical principles of the study and is approved by the Council for the Ethical Issues of Biomedical Research. Information obtained from the questionnaire includes the following: information about the pregnancy (number of the pregnancy, the 
trimester, process of the pregnancy), the level of awareness of the oral health condition during the pregnancy, the general health condition (existence of the chronic diseases), condition of the socioeconomic condition (education, employment, financial situation, social support), medical insurance and availability of the dental service, questions describing the dental behaviors (oral care practice, frequency of the visits to the dentist).

The questionnaire is attached by the purpose of the survey, the method of the survey, and a written consent sheet for participation in the survey. After getting acquainted, the respondents signed a written consent and filled out a questionnaire, and then their oral cavity was examined. The oral health of the target group representatives was assessed by periodontal indices, the CPITNindex, which is used in the determination of the need for treatment of periodontal inflammation, destruction of plaque, stone, and OHI-Jack R.Vermillion's oral hygiene index, which determines the level of hygiene. The target group of the study was 222 pregnant women aged 18 to 45 living in Tbilisi. Data entry and statistical analysis were carried out using the statistical program SPSS 23.0.

The statistical testing of the difference due to the qualitative variables was carried out using the Pearson's chi-square method; the index of signification $(\mathrm{p})$, which was less than 0.05 , at $(\mathrm{p}<0.05)$ was considered as statistically significant.

\section{Results and Discussion:}

The current pregnancy for most of the respondents (36\%) is the second, for $33.3 \%$ of the pregnant women the current pregnancy is the first, and for $23.0 \%$ of the pregnant women, the current pregnancy is the third (Diagram N1). 53.2\% of the respondents were in the second trimester of the pregnancy as of the date of the survey, $17 \%$ of the respondents were in the first trimester of the pregnancy, and $29.7 \%$ were in the third trimester of the pregnancy (Diagram N2) 
Diagram 1. Number of Pregnancy

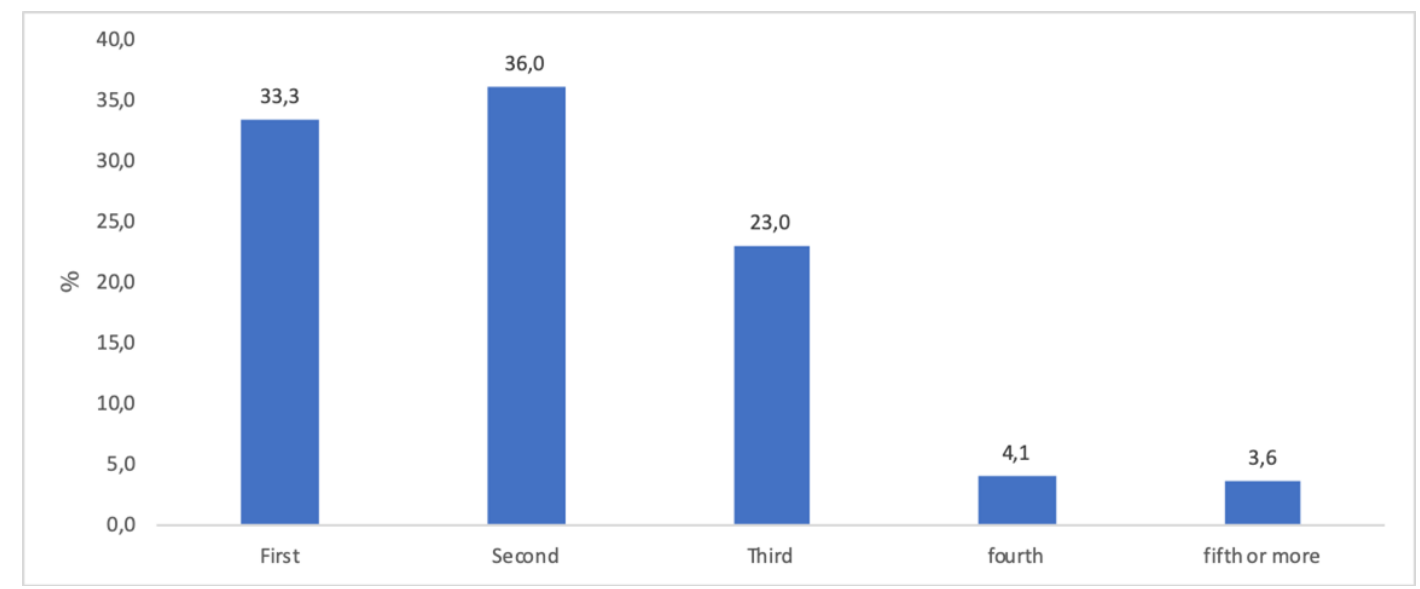

Diagram 1. Pregnancy trimester

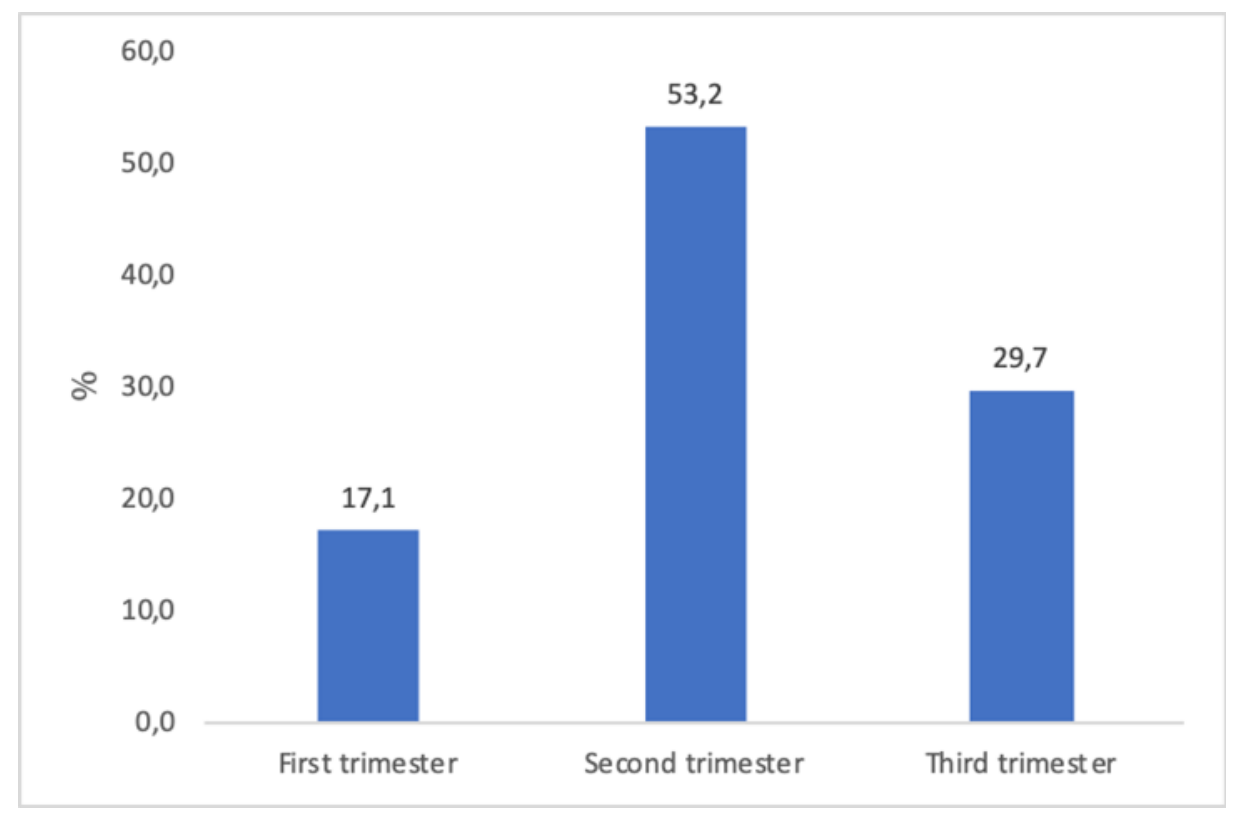

Half of the respondents participating in the survey are bachelors' students or have completed the bachelor's stage of the study. $26 \%$ of them have a secondary education, $13 \%$ have professional education and the smallest is a number of the respondents with masters and doctoral level of education (Diagram N3). 
Diagram 3. Distribution of the respondents due to the levels of education

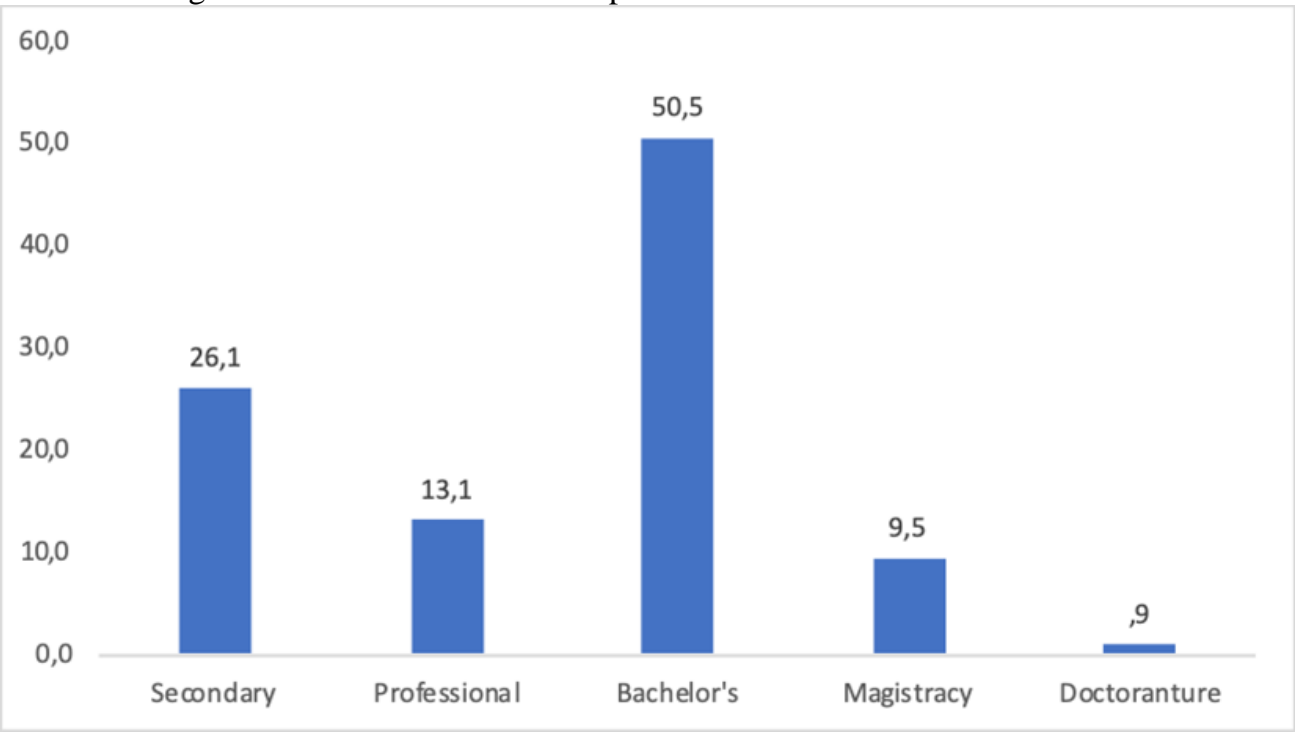

Due to the employment status, $47.7 \%$ of the respondents are housewives. $32,4 \%$ of them are employed in the state sector. $11.3 \%$ are self-employed and $8.6 \%$ of them are employed in the state structures. (Diagram N4), the respondents evaluated their economical condition on a 5-point scale. Most of them evaluate their economical condition as satisfactory $(61.1 \%), 20.8 \%$ as average, and $14.9 \%$ as bad. (Diagram N5)

Diagram 4. Distribution of the respondents due to the employment status

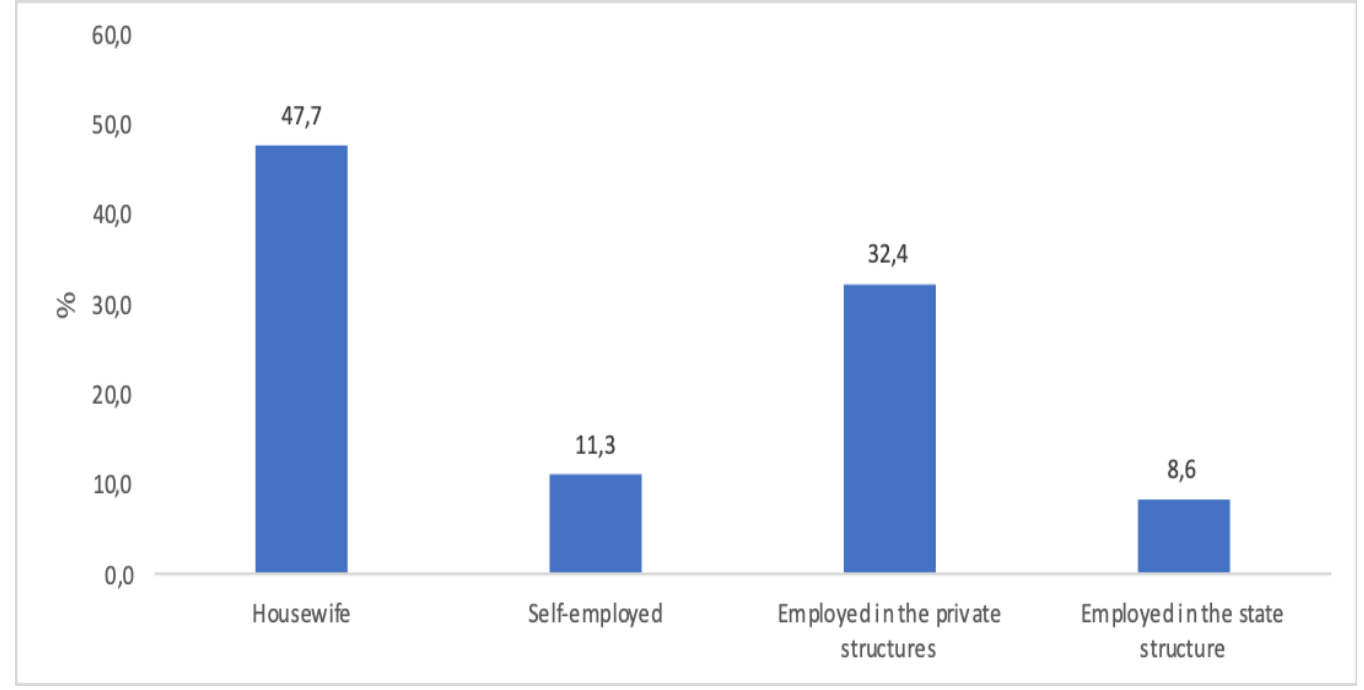


Diagram 2. Distibution of the responders due to the evaluation of their economical conditions

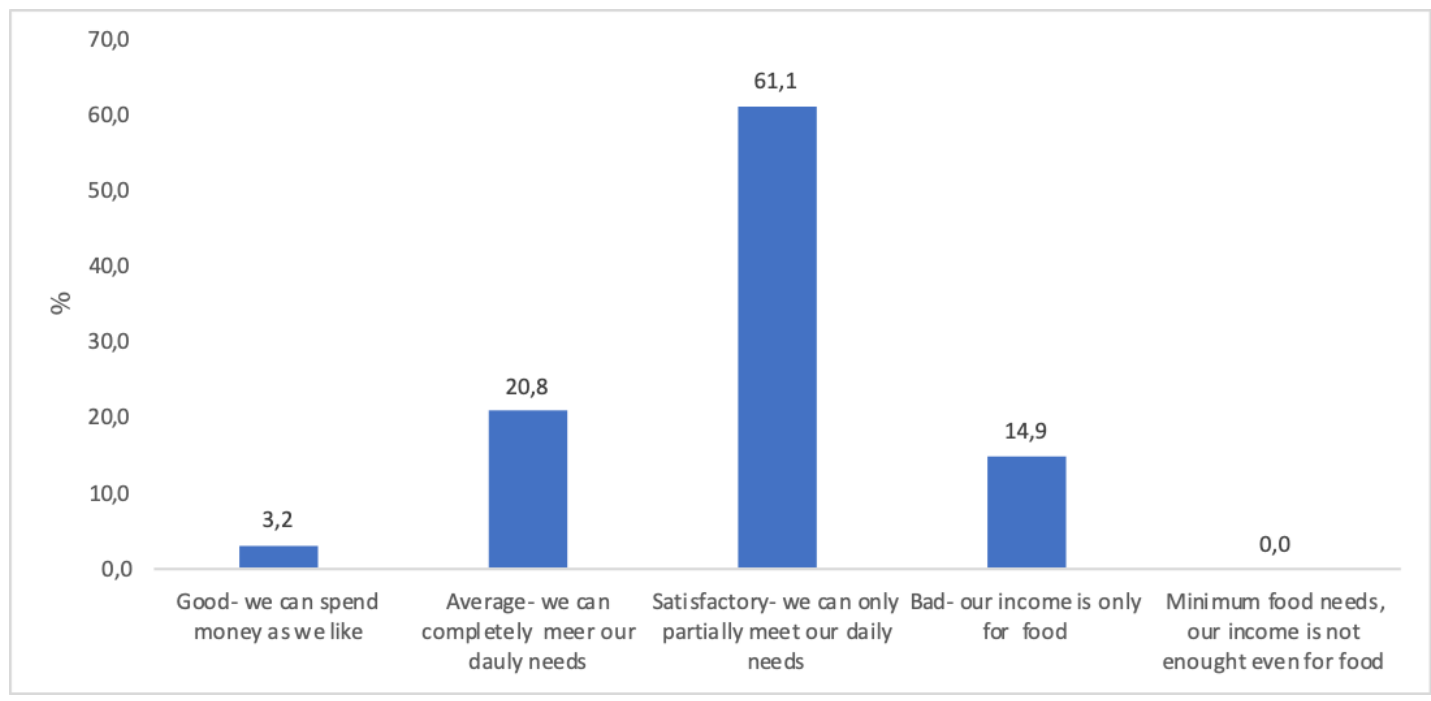

$8 \%$ of the respondents are the beneficiaries of state social benefits, $32.9 \%$ of them have private insurance, $59.1 \%$ of them have state insurance, which does not include a dentist service (Diagram N6; N7)

Diagram 6. Health insurance

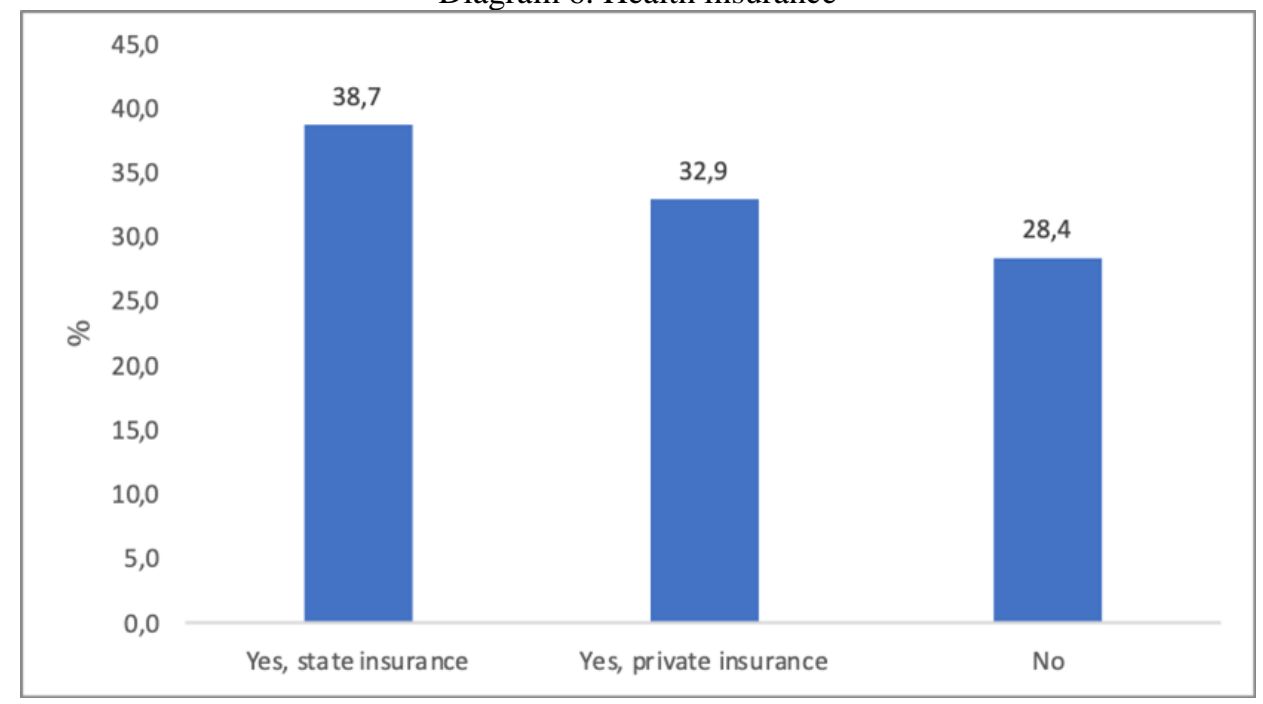


Diagram 7. The shares of the respondents, health insurance of which includes dental services and who have used the dentist services

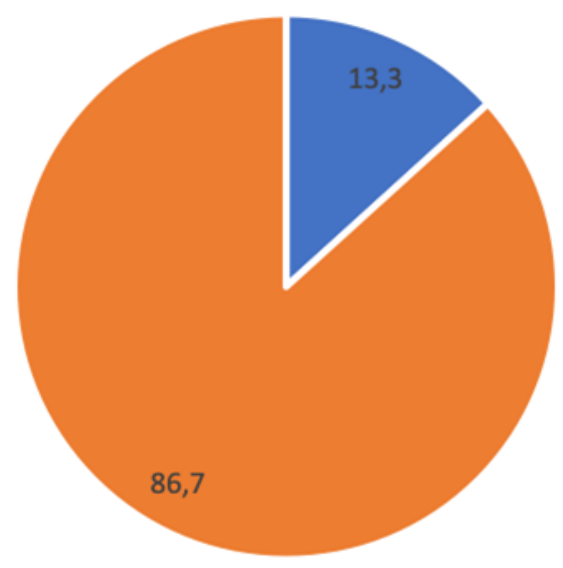

- Have used " Did not use

$13,3 \%$ - did not use

$86,7 \%$ - have used

The correlative analysis showed that there is a moderate positive correlation between financial condition and oral hygiene and such correlation is statistically significant. It means that if the respondent evaluates his financial condition as bad, then the oral hygiene index is higher. (Spearman's rho $=0.372, \mathrm{P}<0.001)$

We received similar results in the correlation analysis between the financial condition evaluation and the CPITN index. There is a positive relatively weak correlation even between these two variables and relations between these variables are statistically significant (Spearman's rho=0.254, $\mathrm{P}<0.001$ ) (Diagram N8). 
Diagram 8. Distribution of respondents due to economic situation evaluation

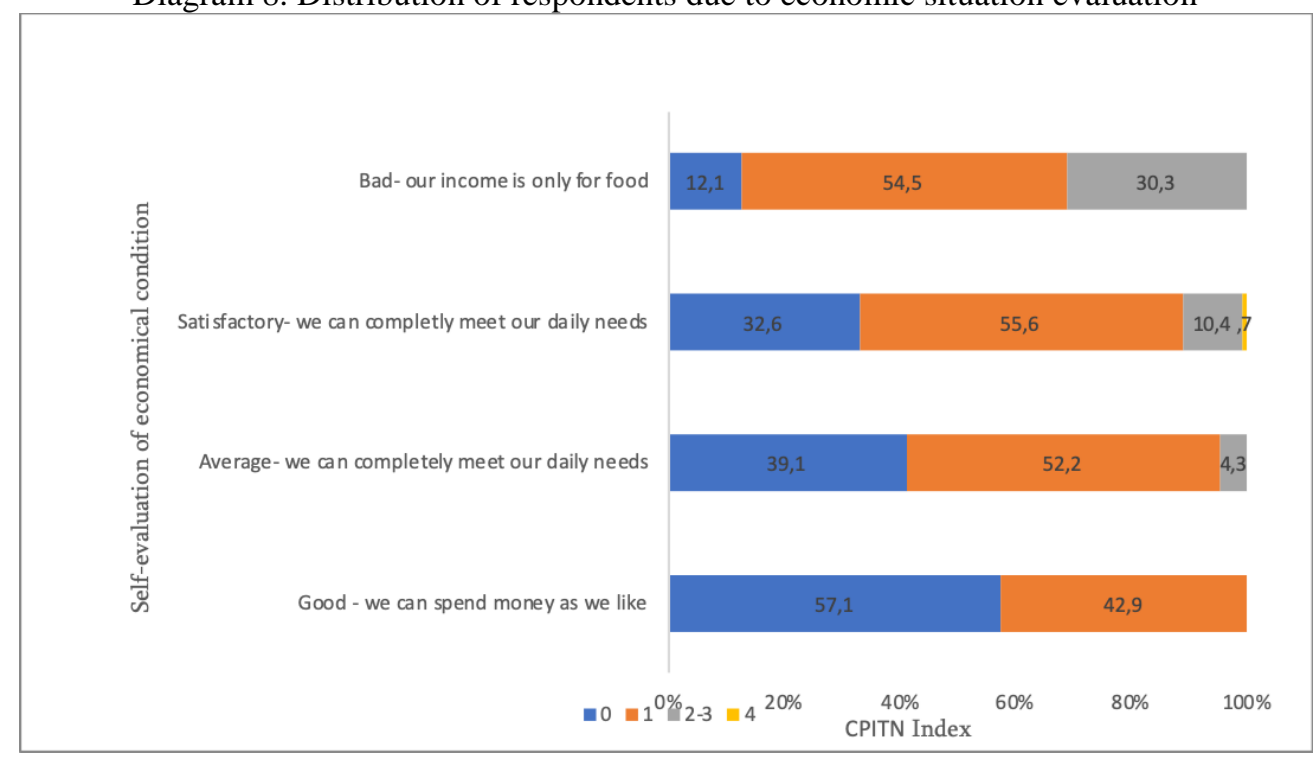

The main reason for the visit to the dentist for $68.8 \%$ of the pregnant women is an emergency/acute condition of their oral health, only $11.7 \%$ of them sometimes visit a dentist for prophylactic control. $23 \%$ of women have been to the dentists during the last 6 months, $25.7 \%$ during the last period from 6 months to 1 year, and $26.6 \%$ of them have been at the dentist's during the period of last $1-3$ years, and $19.8 \%$ more than 3 years ago. (Diagram N6). Furthermore, $18.9 \%$ of pregnant women visited the dentist during the current pregnancy. The emergency/acute cases are named as the main reason for the last visit to the dentists (64\%). (Diagram N10). 
Diagram 9. Frequency of the visit to the dentists

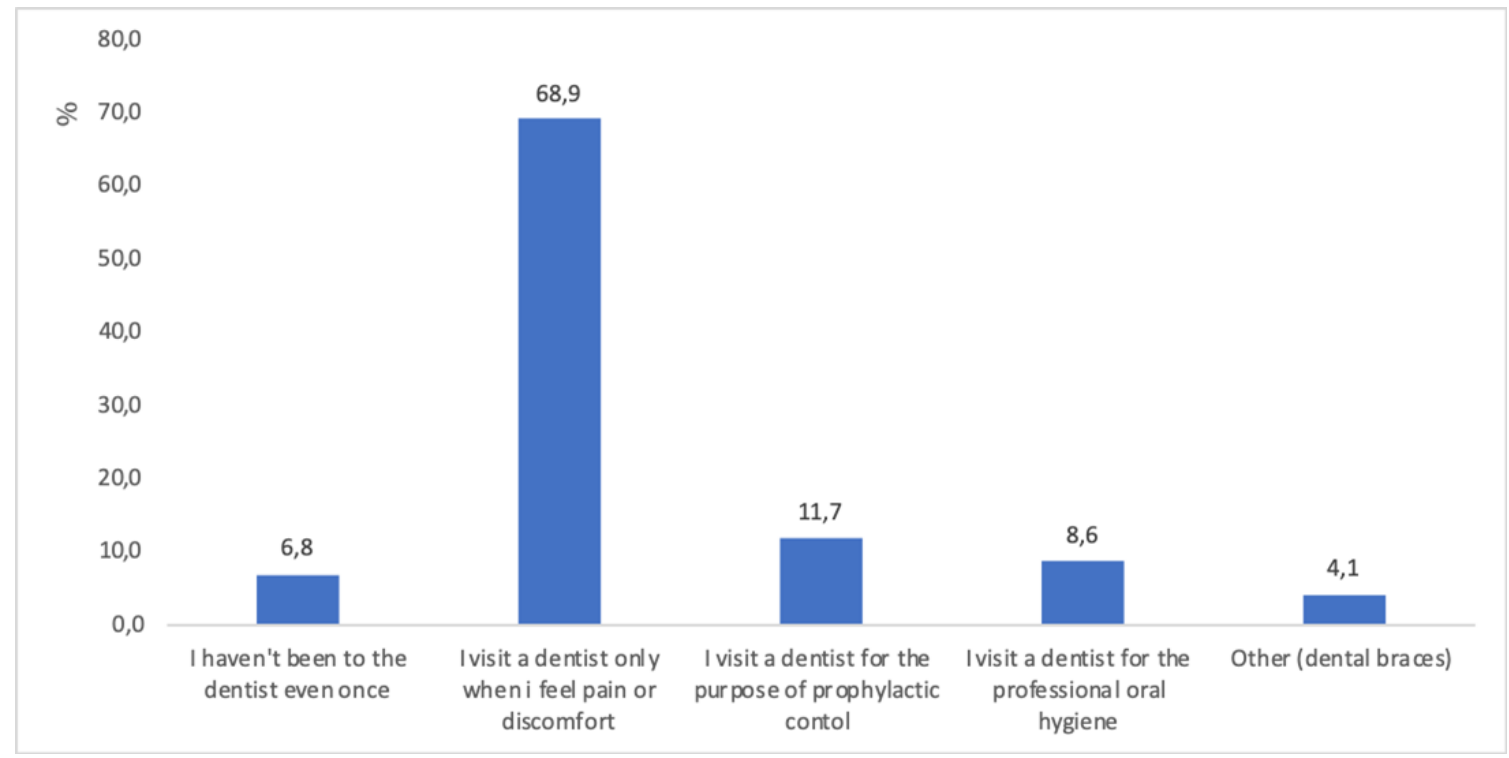

Diagram 10. Last visit to the dentists

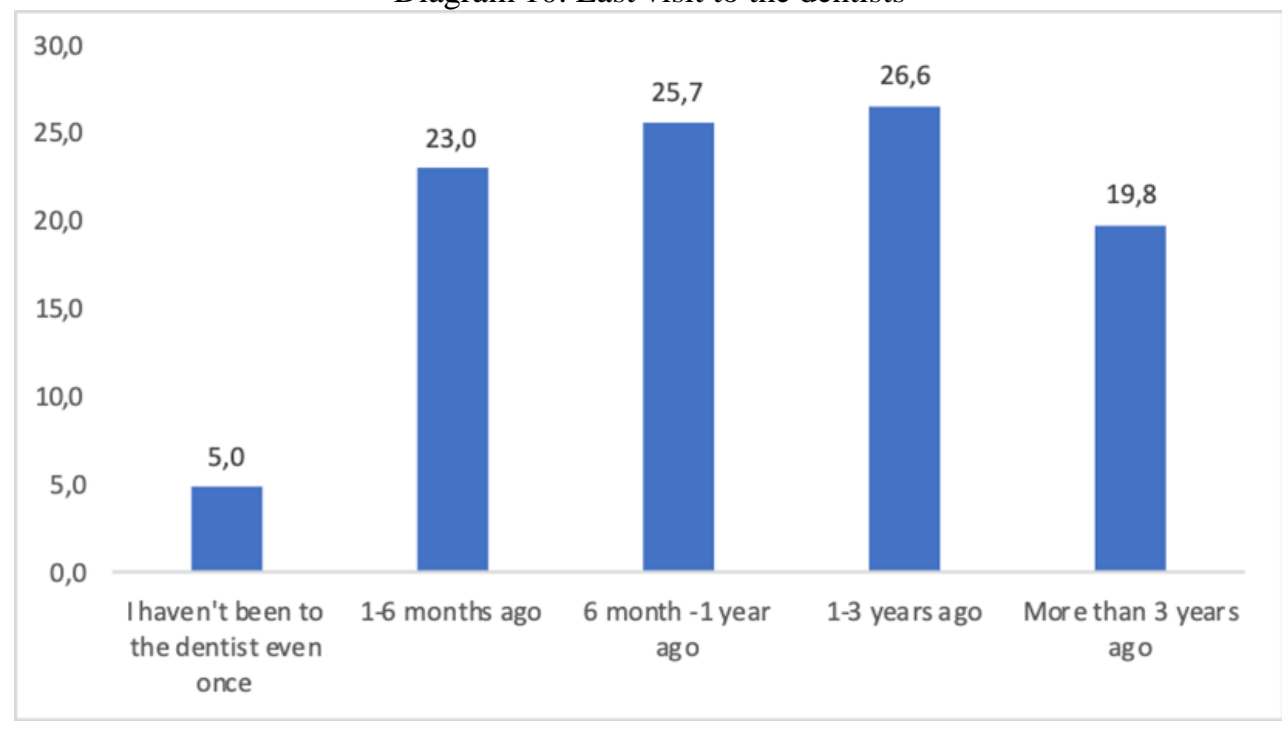

$51.4 \%$ of the respondents note that they do not need to visit a dentist, $32 \%$ note their socio-economic problems, and $13.5 \%$ note that they are scared (Diagram N11). According to the survey only 9\% of gynecologists recommend their patients plan a visit to the dentist. (Diagram N12). 
Diagram 11. Reason for non-regular visits to the dentist

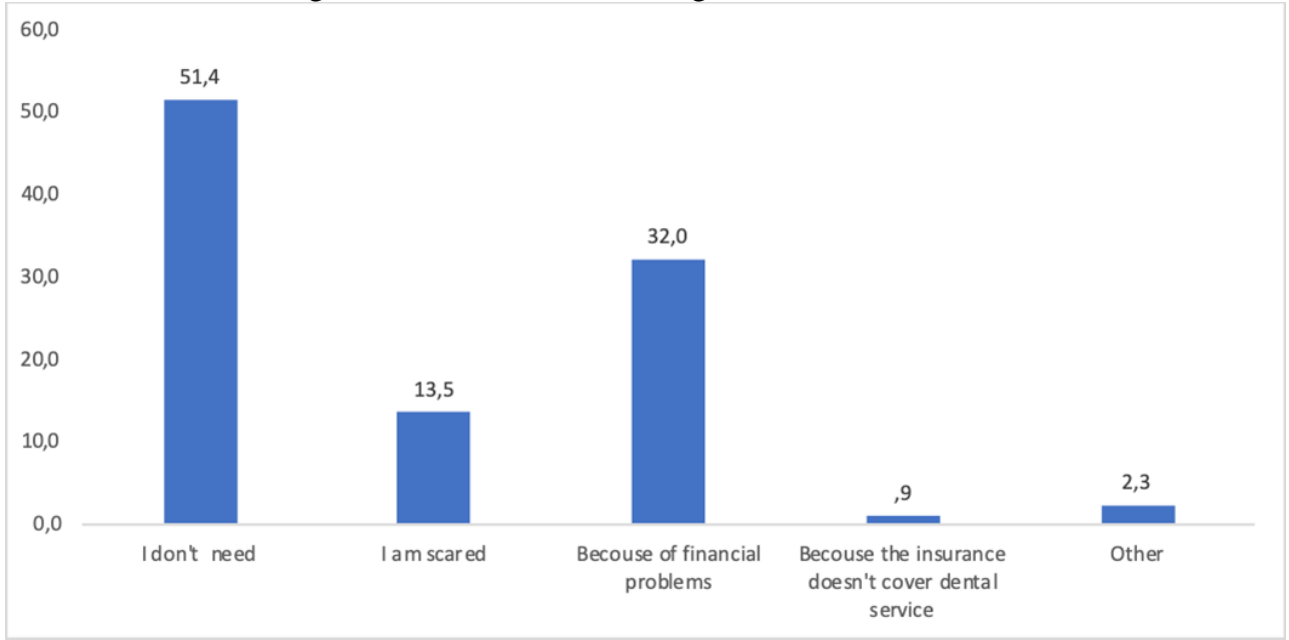

Diagram 12. Recommendations issued by the gynecologists for the visit to the dentist

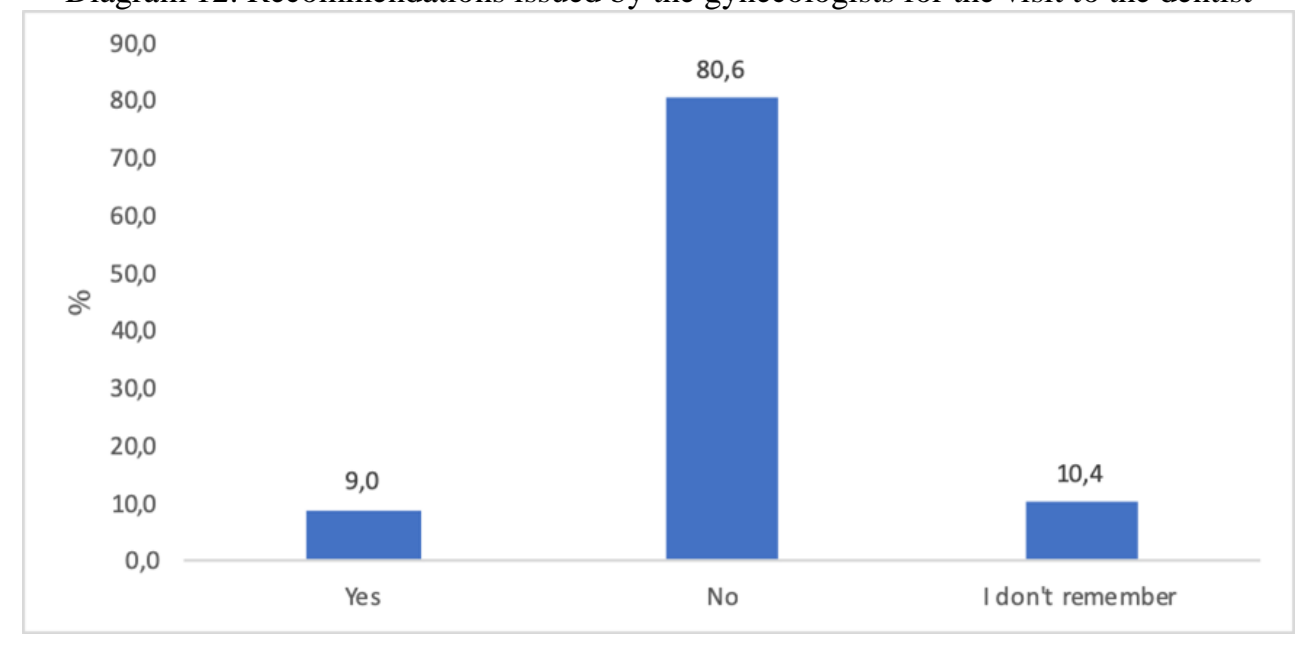

According to our study, most of the pregnant women (55.0\%) mistakenly believe that X-ray examination of teeth and local anesthesia (55\%) are dangerous (diagram N13).

The various types of changes occur in the oral cavity during the pregnancy, which can be associated with inflammatory diseases of periodontal tissue. According to the study results, $67.3 \%$ of the pregnant women have bleeding gums, $66.5 \%$ of them have oral pain/discomfort and $59 \%$ of them have a swelling of the gums/pain of the teeth, $42.8 \%$ of them have an increased sensitivity to the cold food/drinks. The increased sensitivity to hot food/drinks is a relatively rare symptom. None of the listed symptoms are revealed only among $21.6 \%$ of the respondents, and $25 \%$ have at least 3 of the listed symptoms, $35 \%$ have 4 or more of these symptoms (Diagram N14). 
Diagram 13. Awareness of the pregnant women about the safety of the dental manipulations

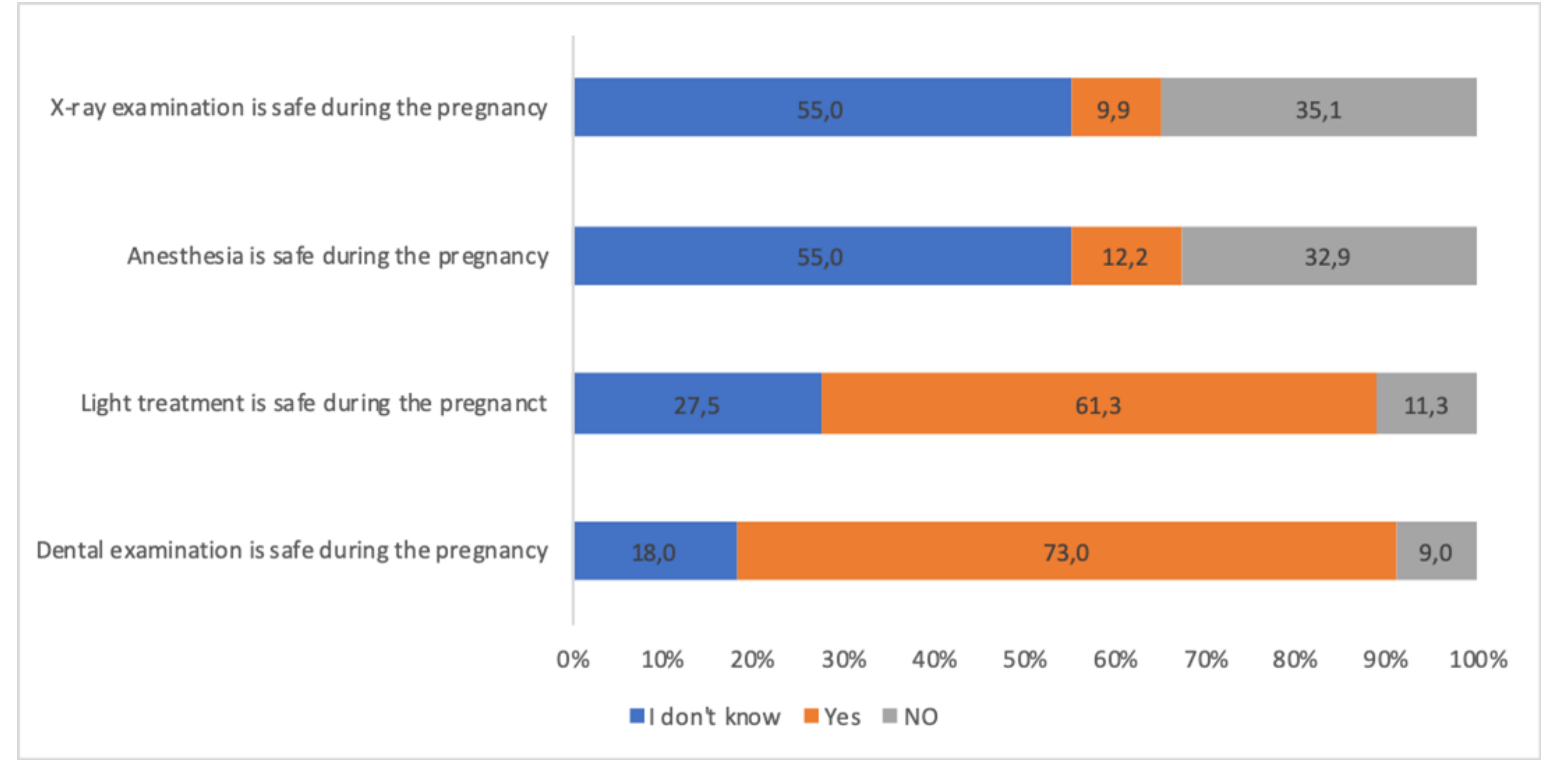

Diagram 14. Self-assessment of the oral health status by the respondents

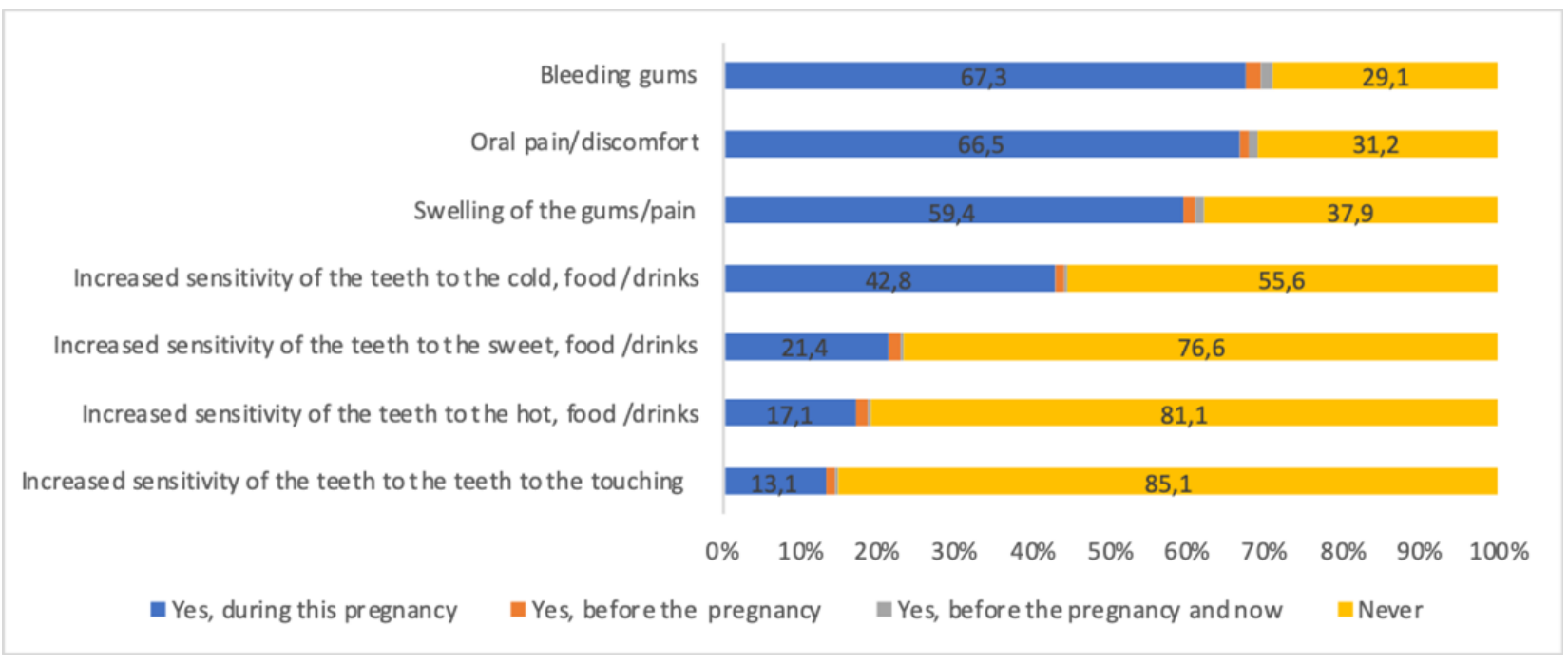

\section{Conclusion}

As the results of our study show the periodontal diseases is distinguished by high prevalence among pregnant women in Tbilisi. $67.3 \%$ of the pregnant women have bleeding gums, $66.5 \%$ of them feel a pain/discomfort in the oral cavity and $59 \%$ of them have swelling/pain in their gums. Also, a variety of risk factors were revealed, such as poor socioeconomic condition, lack of availability to the dental service, low frequency of visits to the dentist, low level of awareness about the oral health importance 
during the pregnancy, which increases the risk of spread of the disease and affects the development of the disease. Therefore, it is important to carry out the screening of periodontal inflammatory diseases to avoid the threats caused by periodontal diseases.

\section{References:}

1. Antenatal surveillance program. (2018) https://nha.gov.ge/ge/c/dedata-da-bavshvta-janmrtelob

2. Chauhan M., Awasthi S. (2017) Interplay of cytokines in preterm birth Monika Pandey. Indian J Med Res 146(3): 316327.doi: 10.4103/ijmr.IJMR_1624_14.

3. Corwin E.J., Hogue C.J., Pearce B., Cherie C.H., Read T.D., Mulle J., Dunlop A.L. (2017), Protocol for the Emory University African American vaginal, oral, and gut microbiome in pregnancy cohort study. BMC Pregnancy Childbirth. 17, 161 https://doi.org/10.1186/s12884-017-1357-x.

4. FDI World Dental Federation. (2017). Tonetti MS, Jepsen S, Jin L, Otomo-Corgel J. Impact of the global burden of periodontal diseases on health, nutrition and wellbeing of mankind: A call for global action. J Clin Periodontol.

5. Fardini Y., Chung P, Dumm R, Joshi N, Han Y.W. (2010) Transmission of diverse oral bacteria to murine placenta: evidence for the oral microbiome as a potential source of intrauterine infection. Infect Immun 78(4): 1789-1796. doi: 10.1128/IAI.01395-09.

6. Jafri Z., Bhardwaj A., Sawai M, Sultan N. (2015) Influence of female sex hormones on periodontium: A case series. J Nat Sci Biol Med 6(Suppl 1): S146-S149. doi: 10.4103/0976-9668.166124.

7. Katz J., Chegini N., Shiverick K. T., Lamont R. J. (2009) Localization of P. gingivalis in preterm delivery placenta. J Dent Res. 88(6):575-8. doi: 10.1177/0022034509338032.

8. Kandelman D., Arpin S, Baez R..J, Baehni P.C., Petersen P.E..(2012) Oral health care systems in developing and developed countries. Periodontol 60(1):98-109. doi: 10.1111/j.1600-0757.2011.00427.x.

9. Kouis P., Kinni P., Rigas A., Papadouri T., Panayiotis K. Theodorou M. (2018) Maternal socioeconomic factors and the risk of premature birth and low birth weight in Cyprus: a case-control study Paraskevi Stylianou-Riga. Reprod Health . 2018 Sep 19;15(1):157. doi: 10.1186/s12978-018-0603-7.

10. Könönen E., Gursoy M, Gursoy U.K. (2019) Periodontitis: A Multifaceted Disease of Tooth-Supporting Tissues. J Clin Med 31;8(8):1135. doi: 10.3390/jcm8081135. 
11. Li H, Wang J, Wu L, Lou J., Liang X., Xiao B., Zhu Y. (2018) The impacts of delivery mode on infant's oral microflora. Sci Rep 8, 11938. https://doi.org/10.1038/s41598-018-30397-7

12. Marin C., Segura-Egea J.J., Martínez-Sahuquillo A., Bullón P. (2005) Correlation between infant birth weight and mother's periodontal status. J Clin Periodontol https://doi.org/10.1111/j.1600051X.2005.00661.X

13. Muwazi L., Rwenyonyi C.M., Nkamba M., Kutesa A., Kagawa M., Mugyenyi G., Kwizera G., Okullo I. (2014) Periodontal conditions, low birth weight and preterm birth among postpartum mothers in two tertiary health facilities in Uganda. BMC Oral Health 28;14:42. doi: 10.1186/1472-6831-14-42.

14. Mathew RJ, Bose A, Prasad JH, Muliyil JP, Singh D. (2014). Maternal periodontal disease as a significant risk factor for low birth weight in pregnant women attending a secondary care hospital in South India: a case-control study. Indian J Dent Res. 25:742-7. https://doi.org/10.4103/0970-9290.152184.

15. Morelli E.L., Broadbent J.M., Leichter J.W., Thomson W.M. (2018). Pregnancy, parity and periodontal disease. Aust Dent J https://doi.org/10.1111/adj.12623.

16. Periodontal Disease and Pregnancy Outcomes: Time to Move On? SindhuK. Srinivas, M.D., MSCEcorresponding author and Samuel Parry,

M.D.2012https://www.ncbi.nlm.nih.gov/pmc/articles/PMC3270055/.

17. Relationship between preterm birth and post-partum periodontal maternal status: a hospital-based Romanian study C Micu , A Roman , F Ticala, A Soanca, A Ciurea, A Objelean, M Iancu, D Muresan, G V Caracostea.2020 https://pubmed.ncbi.nlm.nih.gov/32274638.

18. Riewe S.D., Mans J.J., Hirano T., Katz J., Shiverick K.T., Brown T.A., Lamont R.J. (2010) Human trophoblast responses to Porphyromonas gingivalis infection Molecular Oral Microbiology, 01 25(4):252-259 DOI: 10.1111/j.2041-1014.2010.00573.x PMID: 20618699 PMCID: PMC3665294.

19. Ring M.E. (2002). W.D. Miller The pioneer who laid the foundation for modern dental research. N Y State Dent J 68(2):34-7. PMID: 11898270.

20. Sree G. N., Jayasheela M., Vinayaka A.M., Gayathri G.V., Mehta D. S. (2020) Knowledge and Awareness among Gynecologists in Davangere about the Association between Periodontal Disease and Pregnancy Outcomes and Referral Pattern of Pregnant Woman to Periodontists - A Cross Sectional Survey International Journal of 
Health Sciences and Research Vol.10; Issue: 8; https://www.ijhsr.org/IJHSR_Vol.10_Issue.8_Aug2020/30.pdf.

21. Vanterpool S.F., Tomsin K., Reyes L., Zimmermann L.J., Kramer B.W., Been J.V. (2016) Risk of adverse pregnancy outcomes in women with periodontal disease and the effectiveness of interventions in decreasing this risk: protocol for systematic overview of systematic reviews Sizzle. Syst Rev.5: 16. doi: 10.1186/s13643-016-0195-7.

22. Vollrath J.T., Relja B. (2019) Cytokines in Inflammatory Disease Shinwan Kany. Int J Mol Sci 28;20(23):6008. doi: 10.3390/ijms20236008.

23. Walia M., Saini N. (2015) Relationship between periodontal diseases and preterm birth: Recent epidemiological and biological data. Int $\mathbf{J}$ Appl Basic Med Res 5(1): 2-6. doi: 10.4103/2229-516X.149217.

24. Yenen Z., Ataçă̆ T. (2019). Oral care in pregnancy. J Turk Ger Gynecol Assoc. 20(4): 264-268. doi: 10.4274/jtgga.galenos.2018.2018.0139.

25. Yang I., Hu, Y.J., Corwin E.J., Dunlop A.L. (2016). Exploring the maternal and infant Oral Microbioms. J Perinat Neonatal Nurs. 34(3):211-221. doi: 10.1097/JPN.0000000000000494. 